\title{
EFFECTS OF SURFACE FINISH AND MATERIAL OF CONSTRUCTION OF THE SEPARATING SURFACE ON HIGH-TENSION ELECTRICAL SEPARATION
}

\author{
A.J.W. ROZELAAR ${ }^{\star}$ AND I.S. WELLS ${ }^{\ddagger}$ \\ ${ }^{\star}$ The Highways, Beach Hay, Clows Top, Kidderminster, England \\ $\ddagger_{\text {Boxmag-Rapid Ltd., Aston, Birmingham B6 4AJ, England }}$
}

\begin{abstract}
Tests with a roll type electrostatic separator have shown that the separation of minerals is affected by the material from which the roll is constructed as well as the surface finish of the roll. Experiments have been carried out with single mineral species on roll constructed of titanium, chromium-plated mild steel and aluminium with differing surface finishes. The results indicate that the surface finish influences the separation of the minerals. The effect is attributed to alteration either to the field configuration in proximity of the roll or to the particle-roll capacitance/resistance.
\end{abstract}

(Received January 12, 1993, revised July 3, 1993)

\section{INTRODUCTION}

The basic work from which the investigation described here originated is described in the paper read to the IEE-IAS annual meeting at Toronto in 1978 [1]. As a result of that study it was considered worthwhile conducting tests on a roll type electrostatic separator to discover whether the forces found to operate when electrical contacts separate could be applied to improving mineral separation.

Since the force was dependent upon the capacitance between the contacts, it appeared that the configuration of the roll and particles might give rise to useful differences in the separation characteristics. Although the final departure of the particle from the roll occurs in an electrostatic field, the initial electrical action, when the particles are under the influence of a corona discharge, is taking place 
under conditions of current flow and is therefore analogous to the phenomena previously described [1].

In its commonest form, the electrostatic mineral separator incorporates a rotating cylinder which often has a chromium-plated or polished stainless-steel surface. Little emphasis is placed upon the effects of the surface on the separation of minerals, or on the effect of particular separating surfaces.

Gilbert and George [2] investigated the effect of different metal surfaces, including brass, chromium, duralium and stainless steel. Of these, chromium was considered most suitable for electrostatic separation.

Hudson [3] investigated electrostatic plate type separators and compared shellaced brass, brass, solid copper, mild steel, copper-plated brass and chrome-plated brass. He attributed the differences found to alteration in contact potential between different materials and to the degree of tarnish on the surface of the plate.

Johnson [4] adapted his electrostatic separator for particle sizing by roughening the surface to 'diminish sliding', i.e. to increase the amount of friction between the particle and the roll. None of these investigators related the surface finish quantitatively to the results observed.

The initial aim of the authors' work was to investigate the effect of different materials for the construction of the roll. Differences in the surface finish of the separating roll surface will arise during manufacture. These differences will be governed by the nature of the manufacturing process and the properties of the metals used.

Except for Johnson [4], previous workers did not attempt to control and measure the actual finish, but in this work the finishes were controlled and measured by the stylus profilometer method using the Centre Line Average convention (CLA). A laboratory electrostatic separator was loaned by Boxmag-Rapid Ltd. for the study [5]. 


\section{EXPERIMENTAL PROCEDURE}

\section{Distribution Analyser}

The system of trays and splitters supplied with the separator was unsuitable for obtaining a detailed picture of the distribution of the products. A method of accurately analysing the distribution of the products is described in the literature $[6,7]$. Consequently, a distribution analyser consisting of sixteen $25 \mathrm{~mm}$ wide trays was deployed. These trays were clipped together underneath the separator to collect the products (Figure 1).

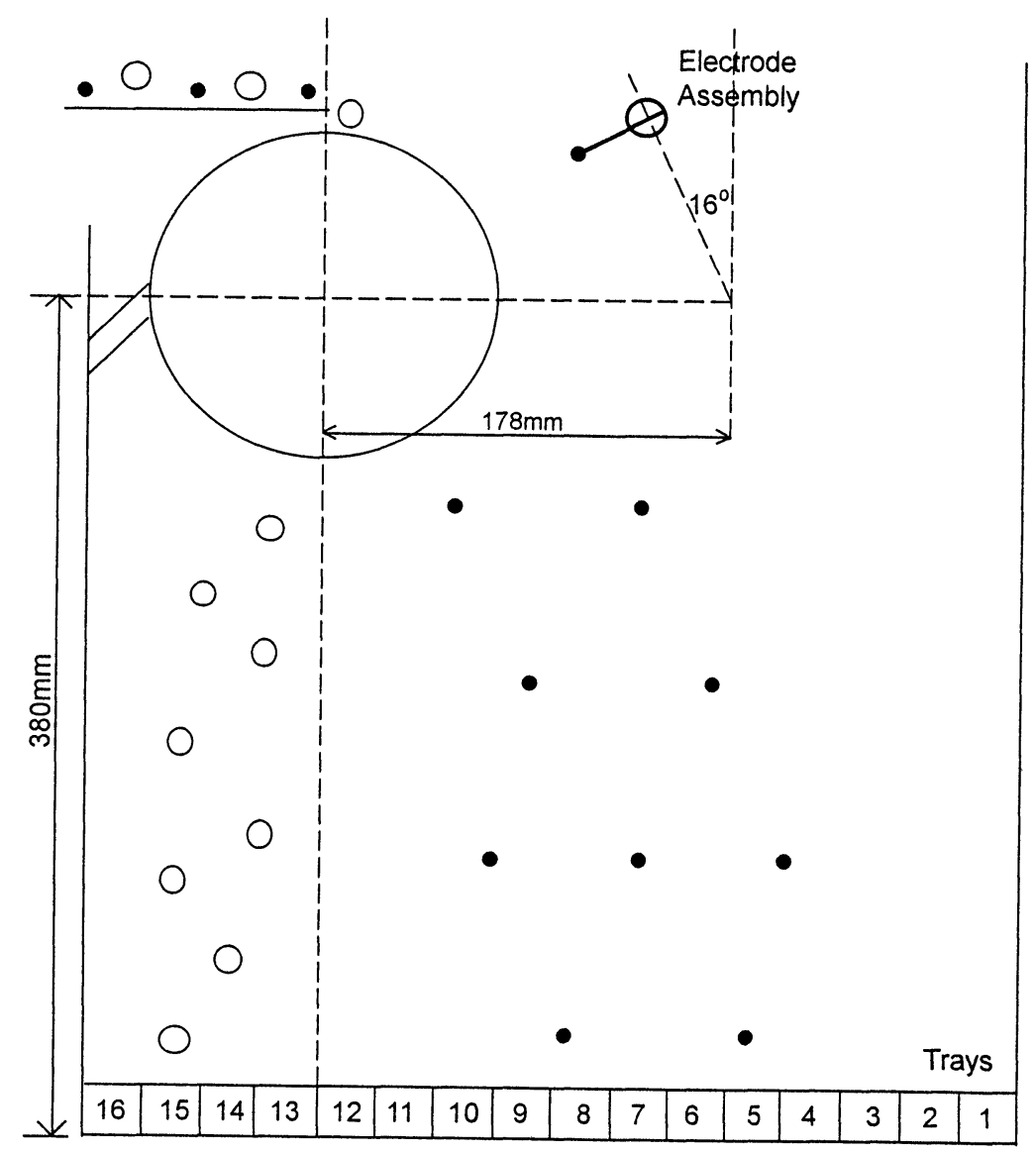

FIGURE 1 Laboratory separator, as modified, showing tray numbering and typical product trajectory 


\section{Selection of Minerals}

In choosing the mineral feed to be used in the experimental work, two factors were considered:

1. The minerals should be easily obtainable in a clean state and be devoid of any surface contaminants such as flotation reagents which could alter their surface conductivity as compared with the natural state.

2. The specific gravity of the various minerals should be similar so as to minimise ballistic differences and enable results to be compared.

Based on these criteria the following minerals were chosen: magnetite, barite (non-porous), cassiterite, barite (porous), ilmenite and garnet.

\section{Preparation of Minerals}

Every precaution was taken not to contaminate the samples with other minerals, grease etc. The size range $-0.85+0.70 \mathrm{~mm}$ was chosen for study since it is suitable for electrostatic separation and large enough to observe visually whilst narrow enough to avoid separation due to ballistic effect. Before crushing and sizing, the material was hand-picked to maintain maximum purity.

\section{$\underline{\text { Roll Speed }}$}

A standard roll speed of $100 \mathrm{rpm}$ was selected.

\section{Moisture Content of the Mineral Samples}

The presence of water on the surface of the particles affects the surface conductivity and hence the rate of loss of charge, which is an important separation factor. In order to ensure that all traces of moisture were removed from the surface 
of the minerals, the heater above the feed chute was employed. Experiments indicated that the role of the heater in removing moisture was more important than its heating effect as such [8].

\section{Electrode Position}

The position of the electrode was fixed as shown in Figure 1.

\section{Feed Rate}

Preliminary tests showed that reproducible results were difficult to obtain at feed rates exceeding a monolayer on the roll. This rate corresponds to $50 \mathrm{~kg}$ per $25 \mathrm{~mm}$ width of roll per 24 hours (for material $-0.85+0.70 \mathrm{~mm}$ ), approximately a quarter of commercial feed rates.

\section{Applied Voltage}

The magnitude and also the polarity of the voltage applied to the active electrode affects the charge acquired by a particle and hence its path through the separator. At all voltages this charge is influenced by the particle/roll electrical contact resistance, size, electrical resistance and the time during which it remains under the influence of the field. At voltages below the onset of corona discharge, the electrical capacitance of the particle is of greater importance than at higher voltages.

When the potential gradient is great enough to give them sufficient charge, non-conducting particles will remain almost totally pinned, while semiconductors and even conductors, will be pinned for part of the revolution of the roll $[5,9]$. According to Kelly and Spottiswood [10] conductors are materials with a conductivity $>10^{5} \mathrm{~S} / \mathrm{m}\left(\Omega^{-1} \mathrm{~m}^{-1}\right)$ and non-conductors with a conductivity $<10^{-8} \mathrm{~S} / \mathrm{m}$. 
In order to assess the performance of different rolls the distribution of mineral in the analyser was determined at $0 \mathrm{kV}, 6 \mathrm{kV}$ and then at intervals of $2 \mathrm{kV}$ up to the sparkover voltage, for both negative and positive electrode polarities. The high voltage supply was half wave rectified with a smooth output.

\section{Physical Properties of the Minerals}

The physical properties of the minerals, i.e. specific gravity, moisture content and specific surface area, were determined on the $-0.85+0.70 \mathrm{~mm}$ size fraction and are presented in Table I.

TABLE I Physical properties of the minerals used in the experimental work

\begin{tabular}{||l|l|l|l||}
\hline \hline MINERAL & $\begin{array}{l}\text { SPECIFIC } \\
\text { GRAVITY }\end{array}$ & $\begin{array}{l}\text { MOISTURE } \\
\text { CONTENT } \\
\%\end{array}$ & $\begin{array}{l}\text { SPECIFIC SURFACE } \\
\text { AREA (BET METHOD) } \\
\mathrm{m}^{2} / \mathrm{g}\end{array}$ \\
\hline \hline Magnetite & 4.87 & 0.174 & 0.414 \\
\hline $\begin{array}{l}\text { Barite } \\
\text { (non-porous) }\end{array}$ & 4.46 & 0.063 & 0.048 \\
\hline Cassiterite & 6.47 & 0.037 & 0.087 \\
\hline $\begin{array}{l}\text { Barite } \\
\text { (porous) }\end{array}$ & 3.98 & 0.030 & 0.520 \\
\hline Garnet & 3.87 & 0.015 & 0.049 \\
\hline Ilmenite & 4.61 & 0.022 & 0.053 \\
\hline
\end{tabular}

\section{Chemical Properties of the Minerals}

The chemical composition of the three metallic minerals was determined by standard wet chemical analysis, the results of which are given in Table II.

Mass spectroscopic analysis of the two barite samples indicated that the main impurity was strontium which was lower than $0.2 \%$. The actual chemical and 
mineralogical composition will determine the bulk electrical resistance of the mineral. The presence of trace impurities may control rectifying properties. (In order to avoid confusion, the term 'rectifying' is used here to denote what in common parlance is termed 'semiconducting').

TABLE II Chemical composition of the minerals used in the experimental work

\begin{tabular}{|c|c|c|c|c|c|}
\hline Mineral & $\mathrm{Fe} \%$ & Ti\% & Sn\% & $\mathrm{SiO}_{2} \%$ & $\mathrm{Al} \%$ \\
\hline Magnetite & 68.92 & 0.205 & $--\cdot$ & 0.86 & ---- \\
\hline $\begin{array}{l}\text { (Stoichiometric } \\
\text { composition) }\end{array}$ & 72.4 & --.- & --- & --- & --- \\
\hline Cassiterite & 0.5 & --- & 74.1 & 0.6 & 0.1 \\
\hline $\begin{array}{l}\text { (Stoichiometric } \\
\text { composition }\end{array}$ & --- & ---- & 78.6 & --- & ---- \\
\hline Ilmenite & 29.6 & 33.3 & --- & --- & --- \\
\hline
\end{tabular}

\section{$\underline{\text { Roll Degreasing and Surface Finish Measurements }}$}

Degreasing of the rolls prior to the commencement of tests was carried out with trichloroethylene and the surface finish was measured with the Surtronic stylus profilometer immediately after degreasing.

\section{Ambient Temperature and Humidity}

The atmospheric temperature and relative humidity were continuously measured during each test. Ambient temperature variations were found to have no measurable effect on separation. The relative humidity only affected the distribution of a mineral in the catchment trays when it was outside the range 40 to $70 \%$. 


\section{$\underline{\text { Separating Surfaces }}$}

All rolls were manufactured to the same dimensions so that they were interchangeable. For preliminary investigation a titanium roll (surface finish $7092 \mu \mathrm{m}$ CLA) was compared with a chromium-plated roll (surface finish $394 \mu \mathrm{m}$ CLA) as normally fitted to Boxmag-Rapid separators.

It was found that the great difference in the surface finish of these two rolls made it difficult to distinguish between the effect of the material of construction of the roll and that of its surface finish.

In order to differentiate between these two factors, two sets of rolls were manufactured. One set was made of mild steel turned and then lightly polished for surface finishes of $788,1773,3940$ and $4334 \mu \mathrm{m}$ and turned only without polishing for surface finishes of 5713,6304 and $9850 \mu \mathrm{m}$. The other set made of aluminium only had the turning operation performed, no polishing being used. Surface finishes were 1773,2758 and $13396 \mu \mathrm{m}$. Cost prevented the possibility of a similar set of titanium rolls.

Subsequently, four of the mild steel rolls were chromium plated. The surface finishes these plated rolls were 433, 591, 1970 and $3310 \mu \mathrm{m}$ [11].

\section{INITIAL RESULTS}

With the standard chromium-plated and titanium rolls, some pinning of both cassiterite and magnetite was observed below the onset of the corona discharge field, which latter was taken as the voltage at which the HT power supply current meter just showed a deflection (for the electrode settings selected, this was about $12 \mathrm{kV}$ for negative polarities and $17 \mathrm{kV}$ for positive polarities), both minerals being pinned more to the chromium roll then to the titanium roll (Figure 2).

However, above the onset of the corona discharge, both minerals were pinned more to the titanium roll than to the chromium-plated one. 


\section{MEAN TRAY NUMBER}

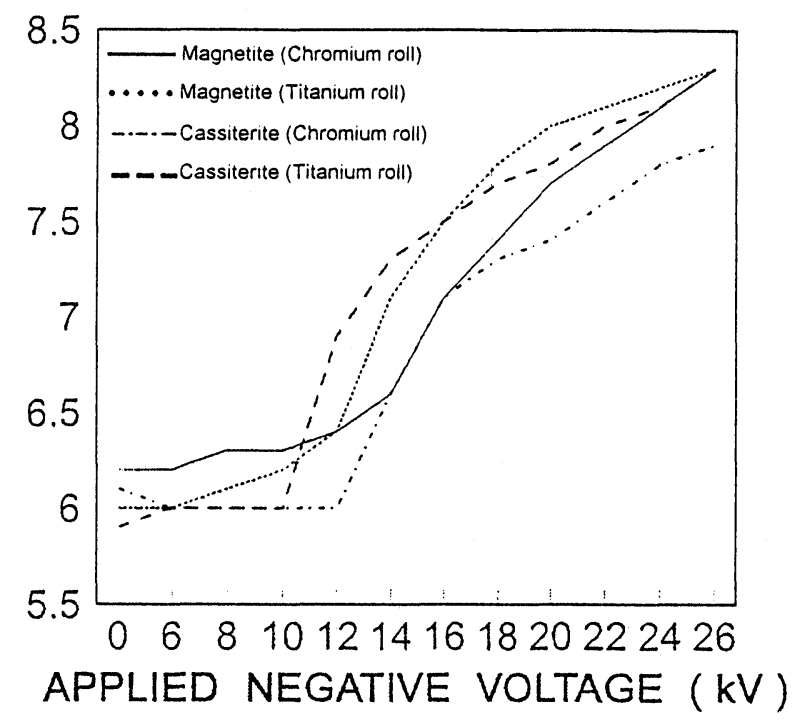

FIGURE 2 Chromium and titanium rolls: relationship between mean tray numbers for cassiterite and magnetite and the applied negative voltage

There was little difference in the behaviour of the non-porous barite on either roll; however, pinning to the rolls at higher voltages was much greater than for cassiterite or magnetite, and even at low voltages, the pinning forces were considerable as would be expected for a non-conductor.

The porous barite was thrown from both rolls to the same extent until the voltage was increased to the onset of the corona discharge when the pinning at first increased rapidly, until $18 \mathrm{kV}$ negative polarity and $22 \mathrm{kV}$ positive polarity, after which the rate of increase of pinning decreased. At negative polarities up to $18 \mathrm{kV}$ the barite was pinned more to the chromium roll whereas above $18 \mathrm{kV}$ the difference diminished until there was slightly more pinning on the titanium roll; at $14 \mathrm{kV}$ the difference was at a maximum (Figure 3). 


\section{Discussion of Initial Results}

The higher relative permittivity of titanium oxide was expected to cause greater pinning to the titanium roll than the chromium-plated one whilst the difference in surface finish was expected to have the opposite effect. If this expectation is correct it would appear from the initial results that surface finish was the over-riding factor.

\section{MEAN TRAY NUMBER}

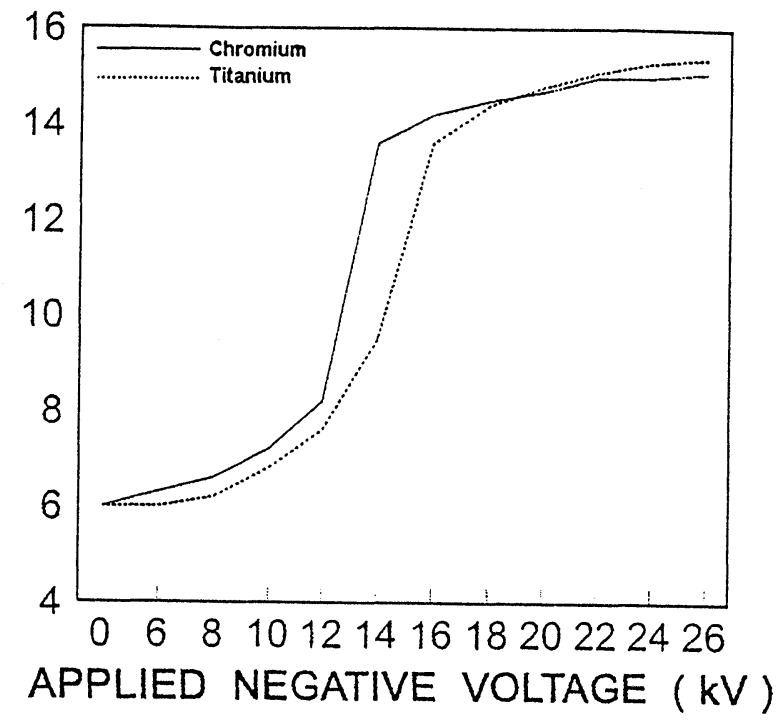

FIGURE 3 Chromium and titanium rolls: relationship between mean tray numbers for barite (porous) and the applied negative voltage

\section{RESULTS WITH CASSITERITE ON MILD STEEL ROLLS OF DIFFERENT SURFACE FINISHES}

In Figure 4 the mean tray number has been plotted against the $\log$ of the mean surface finish for different negative voltages above the onset of the corona discharge. It can be observed that at constant voltage, for rolls with a surface finish smoother than $5713 \mu \mathrm{m}$, the pinning is proportional to surface roughness. With the rolls of greatest surface roughness, less pinning at a particular voltage 
was observed. The difference between the mean tray numbers for the $788 \mu \mathrm{m}$ and $5713 \mu \mathrm{m}$ rolls is equivalent to $37.5 \mathrm{~mm}$ in the position of the ballistic trajectory of the product at tray level with the voltage just above the onset of the corona discharge. On changing to a positive polarity, little difference due to surface finish is observed.

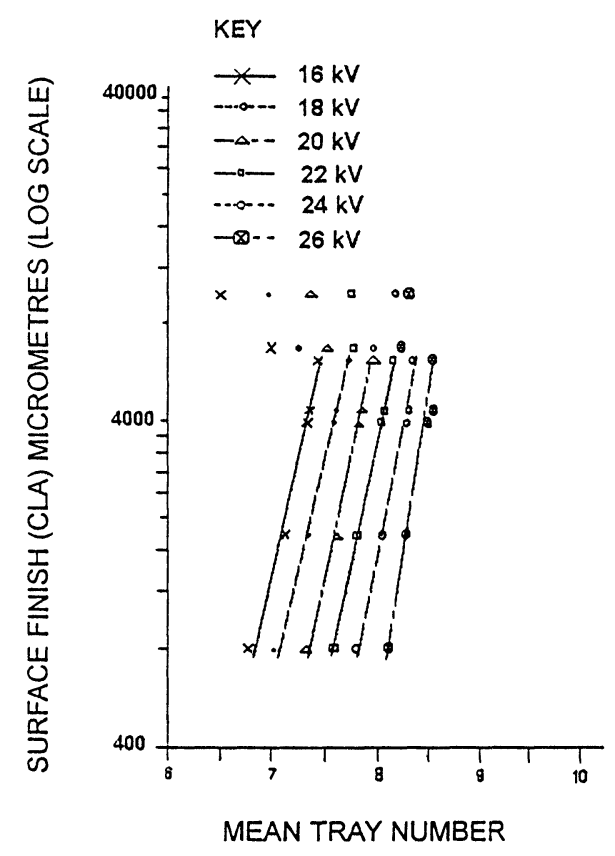

FIGURE 4 Mild steel rolls: relationship between surface finish of roll and mean tray number of cassiterite (showing the discontinuity in the graph at app. $6000 \mu \mathrm{m}$ where the transition from abrasive finish to solely lathe finish occurs).

\section{Comparison Between the Standard Chromium Roll and Mild Steel Rolls}

Between 12 and $22 \mathrm{kV}$ negative polarity, the pinning on the chromium roll is similar to that on the mild steel rolls. Above $22 \mathrm{kV}$ the pinning on the chromium roll does not increase as fast as on the mild steel rolls so that by $26 \mathrm{kV}$ there is less pinning than on any of the steel rolls. On changing to a positive polarity, the pinning of cassiterite on the mild steel rolls was found to be greater than on the chromium roll at all voltages. 


\section{Comparison Between the Titanium and Mild Steel Rolls}

Between 12 and $22 \mathrm{kV}$ negative polarity there is more pinning on the titanium roll than on any of the mild steel ones; however, above $22 \mathrm{kV}$ the pinning on the titanium roll does not increase by as much as it does on the mild steel rolls and at $28 \mathrm{kV}$ the pinning on the titanium roll and on the mild steel one of similar surface finish is alike. With a positive polarity, the pinning on the titanium roll is less than on any of the mild steel rolls.

\section{Discussion of Results Obtained with Mild Steel}

The surface finish appears to be important in determining the amount of pinning when employing a negative polarity. In the case of the rolls for which a linear relationship was found between pinning and $\log$ surface finish, their finish had been achieved by polishing with emery after they had been turned on a lathe, whereas the results obtained with the rougher ones which had been solely turned without any subsequent polishing, no longer lay on the same straight line.

Not only the actual magnitude of this surface finish but also the method by which the surface is achieved and therefore the type of surface appears to be an important consideration. The surfaces of the rolls which had only been turned were observed to consist of circumferential radial lines, while those which had been subsequently polished with emery had lateral lines superimposed on the surface in addition.

\section{RESULTS WITH ALUMINIUM}

No correlation was found between surface finish and the distribution of a particular mineral for either polarity, although there were differences, considerable in some instances, in the behaviour of the minerals on each of the rolls. for barite (non-porous), at the onset of the corona discharge, due to the greater pinning to the aluminium roll, the difference between the mean tray number on the chromium-plated roll and on the aluminium roll with the coarsest finish was equivalent to a displacement of $150 \mathrm{~mm}$. 
In Figure 5, the distribution of barite (non-porous) on titanium, chromium-plated and aluminium rolls at negative applied voltage is shown.

\section{MEAN TRAY NUMBER}

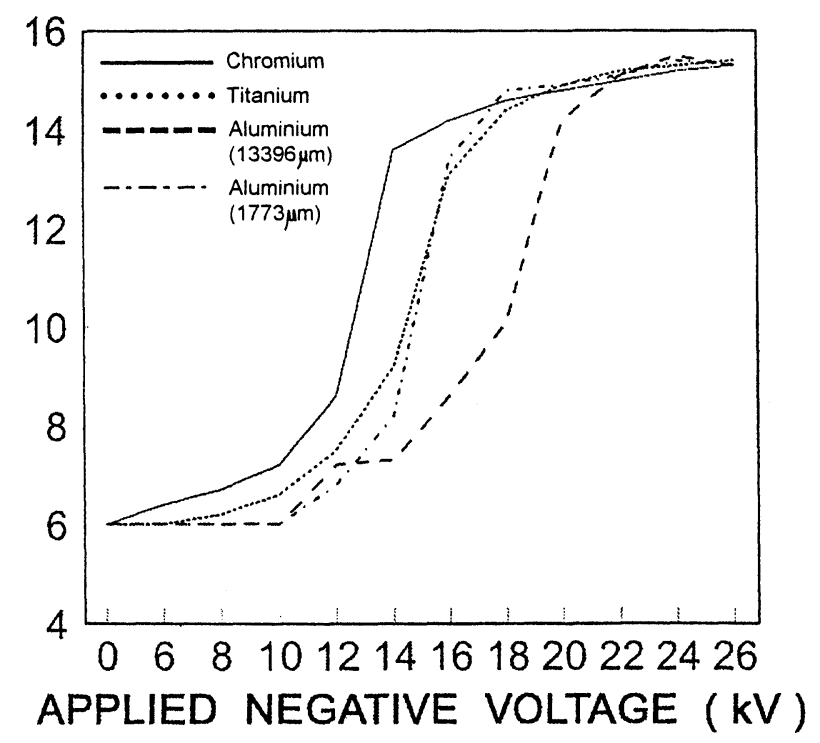

FIGURE 5 Titanium, chromium and aluminium rolls: relationship between mean tray number for barite (non-porous) and the applied negative voltage

Discussion of Results Obtained with Aluminium

It was concluded that, as there was no apparent relationship between mean tray number and surface finish for aluminium, either the oxide film on aluminium was having an overriding effect due to its resistance, or through some rectifying effect, or else that the relationship found for the mild steel rolls depended principally upon the amount of polishing.

\section{GENERAL DISCUSSION}

The effect of different surface finishes may be to: 
1. Alter the actual area of contact between the roll and the particles and therefore alter the particle/roll contact resistance which in turn affects the rate of loss of charge

2. Alter the particle/roll capacitance due to the change in contact area as in (1) above

3. Alter the field configuration and hence the potential gradient close to the roll, thus affecting the total charge received

4. Affect the coefficient of friction between the particles and roll and therefore the speed of the particles through the charging zone, which will determine the charge received and the point of detachment from the roll. This can be observed by comparing the results at no applied voltage for the different roll surfaces when, in general, particles detach from the roll at an earlier point for the smoother surfaced rolls, although contact potential and frictional charging make exact evaluation difficult

5. Affect the degree of oxidation (or chemical alteration) of the surfaces of the roll. It is known that mild steel with a high polish oxidises much more slowly in comparison to mild steel with a rougher finish and this will affect roll/particle contact resistance which will determine the rate of loss of charge as well as the capacitance.

Whereas with negative polarity clear relationships were found on changing to a positive electrode polarity, the difference observed in the behaviour of the minerals on the various mild steel rolls was small. The fact that the surface finish of the mild steel roll does not appear to have much effect when a positive (i.e. with the active electrode positive with respect to the roll) corona discharge field is employed suggests that either:

(a) the different surface finishes of the rolls result in a different field configuration in the negative corona discharge field but not in the positive field, or

(b) the rectifying properties of the cassiterite result in a different behaviour in the negative field, or 
(c) the rectifying effects due to the asymmetrical nature of the electrodes causes a difference in the behaviour of the cassiterite under fields of different polarity.

Kilavuz [12] has subsequently shown that cassiterite exhibits marked rectifying properties whereas magnetite does not and therefore tests should be performed with magnetite and cassiterite under similar conditions to determine whether the rectifying property of the mineral is a controlling factor.

Cobine [13] states that for a negative wire most of the potential drop occurs close to the wire with a similar though much smaller fall of potential at the roll and over a large region the potential gradient remains more or less zero. With a positive wire there is a pronounced fall of potential at the wire and then a gradual fall to the surface of the roll.

He measured the corona potential distribution for a wire within a tube of $70 \mathrm{~mm}$ diameter. The measurements were made by means of an insulated probe and errors in measurements were stated to be insignificant except close to the wire. These potential plots are shown in Figure 6 .
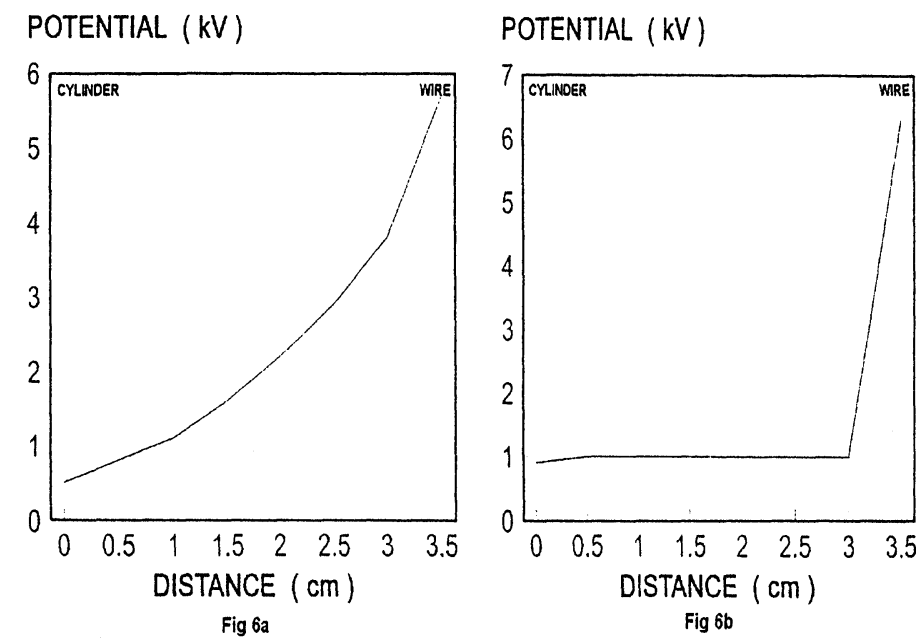

FIGURE 6 Relationship between wire-to-cylinder distance and wire-to-cylinder voltage at a constant current of $1.91 \times 10^{-5} \mathrm{~A}$.

(a) wire positive, (b) wire negative 
The oxidation state of the surface of the roll would probably not be sufficiently affected by a change in polarity to make a material difference in the results. In any case, if an oxidation effect existed it would be expected to be permanent and no permanent change in roll behaviour was observed. Thus, only differences due to the field configuration, which is known to be very different for positive and negative corona discharge fields, together with the roll/particles capacitance and/or resistance which may be a function of the field, remain.

Therefore, unless some other effect or effects which have not been considered are responsible, it seems likely that the surface finish is influencing the mineral separation by virtue of its effect upon the field in close proximity to the roll and/or its effect upon particle-roll capacitance/resistance.

\section{CONCLUSION}

Although with negative electrode polarity a correlation was found between the final trajectory of the mineral particles and the surface finish of the separating surface of the roll prepared by turning followed by polishing, this correlation was not manifest with positive electrode polarity. The number of factors involved in the analyses of the observed results were such that further work is required before a rigorous mathematical treatment can be evolved which will enable a more exact interpretation of the results to be made. A preliminary analysis of the mechanical forces acting has already been published [14] but there is insufficient knowledge to incorporate the electrical and other forces acting.

The apparent lack of specific correlation between surface finish and the final trajectory of a mineral particle when the rolls of aluminium are manufactured solely by turning was unexpected and considerable detailed work may be necessary before the true explanation for this can be found.

The observation that the maximum differences due to surface finish occur when the electrode voltage is close to the onset of corona discharge may be of considerable practical importance. This could be due to the fact that at these voltages, small increases in voltage result in larger current increases than those 
which occur for similar voltage changes outside this region. Small differences in the behaviour of the mineral may therefore be accentuated.

It must be remembered that the onset of the corona discharge will be affected by the relative humidity, temperature and to a lesser extent the air pressure, but Cobine [13] considered the humidity to be the more important effect.

The surface finish of the roll as well as the material of construction of the roll and any oxide layer present may also affect the onset of the corona discharge. However, in the work carried out by the authors, in the range of relative humidities encountered (i.e. between 40 and $70 \%$ ) no correlation was found between these and the onset of corona discharge. Although some apparent correlation between the material of construction of the roll and the behaviour of the mineral was found, much further work is required before this effect can be satisfactorily quantified in isolation from from the other factors influencing the results.

The experimental work described was conducted in the Minerals Engineering Department of the School of Chemical Engineering of the University of Birmingham, England.

\section{REFERENCES}

[1] A.J.W. Rozelaar: "Some aspects of the forces acting when electrical contacts separate", presented at the IEE Industry Application Society Meeting, Toronto, Canada, Oct. 1 - 5, 1978

[2] L.A. Gilbert and G.T. George: Nature (London) 194 (1962), 1068

[3] S.B. Hudson: Proc. Australasian IMM, Sept.-Oct. 1950, 145

[4] H.B. Johnson: Chem. Met. Eng. 50 (1943), 130

[5] I.S. Wells: "Some factors affecting electrical methods of separating minerals", PhD. Thesis, University of Birmingham (1973)

[6] S.C. Sun et al.: Trans. Am. Inst. Min. Engrs. 187 (1950), 369

[7] G. Simkovich et al.: Ind. Engr. Chem. Fund 11 (1972), 274 
[8] M. Carta et al.: "Improvements in electric separation and flotation by modification of energy levels in surface layers", Proc. 10th Intl. Min. Proc. Congress IMM (1973). Contributed remarks pp. 435-437

[9] J. F. Delon: Ann. des Mines (Paris), March 1966, 219

[10] E.G. Kelly and D.J. Spottiswood: Minerals Eng. 2 (1989), 33

[11] I. Cakir: "Some factors of the high tension electrical separation of minerals". PhD Thesis, University of Birmingham (1978)

[12] O. Kilavuz: "Some aspects of test procedures for electrical separation of minerals". PhD. Thesis, University of Birmingham (1979)

[13] J.D. Cobine: Gaseous Conductors. McGraw Hill, New York (1941)

[14] I. Cakir et al.: "A preliminary analysis of the mechanical forces acting on particles on the rotor of an electrical separator". Proc. 12th Intl. Min. Proc. Congress, Sao Paulo, Brazil. Special Publication Vol. 1 (1977), 47
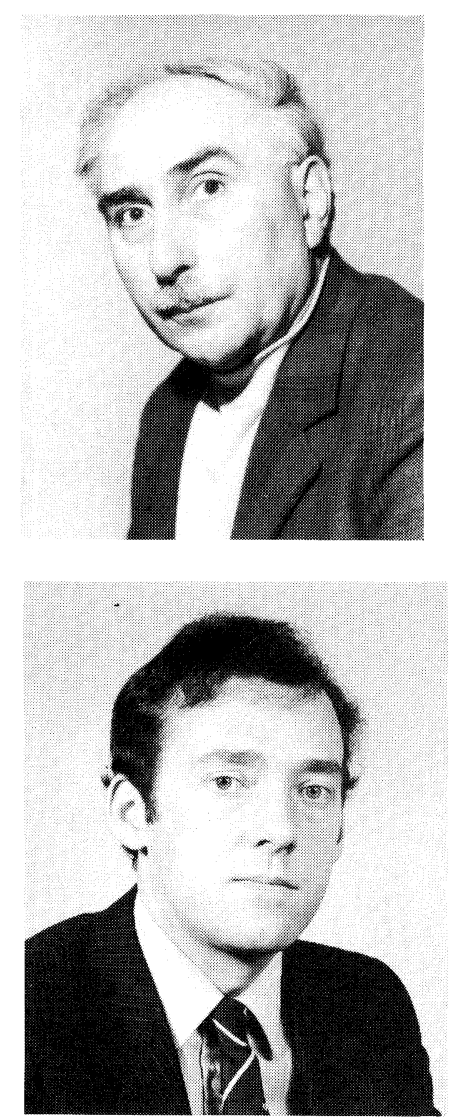

Alan J.W. Rozelaar was educated at Heymers College, Hull, England and spent six years in Anti-aircraft Artillery serving in the UK, West Africa, NW Europe and Burma. After demobilisation he gained an Honours Degree in Mining at the University of Birmingham and spent the next six years mining coal and tin in the UK, and chrome, niobium and titanium in West Africa. Returning to the UK he joined Lucas Gas Turbines, working there until appointed Lecturer in mining at the University of Birmingham, a post he held through various transformations until his retirement. During his final seven years he inaugurated an Honours Degree in Science of Resources. A lifelong interest in amateur radio, involvement with radar during war service and several years part-time lecturing in electrical engineering led to research interests employing aspects of these disciplines. Other research interests include electrical methods of comminution, rheological properties of suspensions, gravity separation and friction. He is now a Fellow of the Institution of Mining and Metallurgy, Fellow of the Institution of Mining Electrical and Mining Mechanical Engineers, Fellow of the British Interplanatory Society and a member of the Radio Society of Great Britain.

I.S. Wells: For biography see Mag. Electr. Sep. 3 (1992), 111

Keywords: electrostatic separator, surface finish, electrode polarity, mild steel, aluminium, titanium and chromium plated rolls 